\title{
Confirming placement of nasogastric feeding tubes
}

\author{
Marie-Andrée Lortie MD, Emmanuel Charbonney MD PhD
}

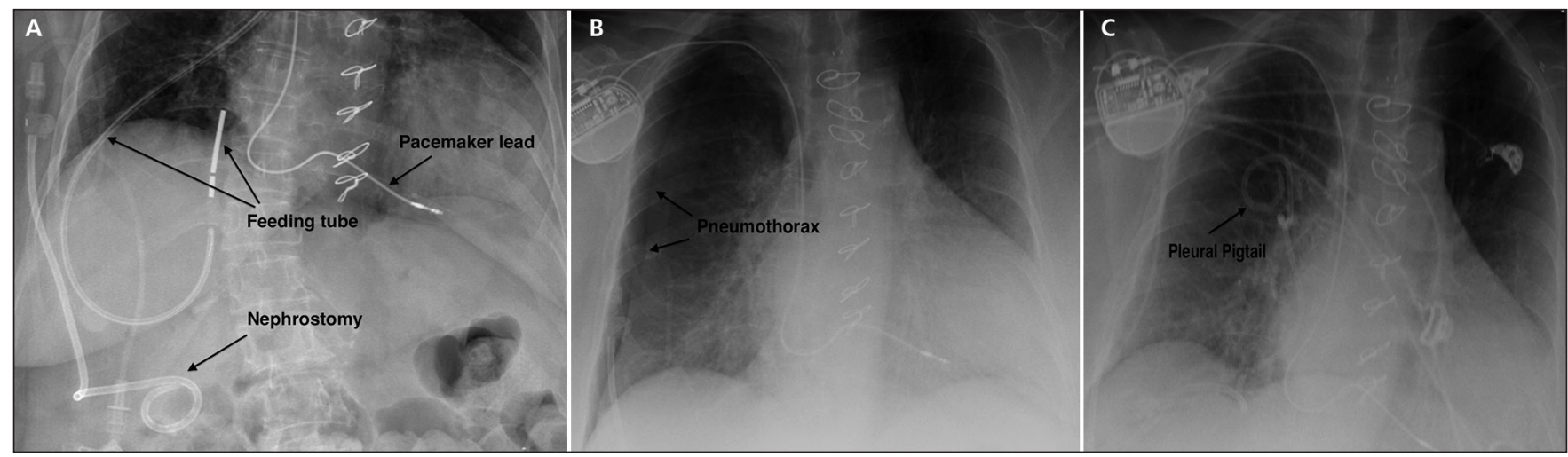

Figure 1: (A) Chest radiograph showing a nasogastric tube with metal guide wire, positioned along the right bronchus and penetrating through the lower lobe into the pleural space in a 78-year-old woman. A right-side nephrostomy, implantable cardioverter defibrillator and poststernotomy wires are also visible. (B) Chest radiograph taken after removal of the tube showing a pneumothorax. (C) Chest radiograph taken after pleural drainage with a pleural pigtail catheter showing the resolved pneumothorax.

Competing interests: None declared.

This article has been peer reviewed.

The authors have obtained patient consent.

Affiliations: Department of Vascular Surgery (Lortie),

Centre de santé et de services sociaux de TroisRivières, Université de Montréal, Trois-Rivières, Que.; Intensive Care Unit (Charbonney), Hôpital du Sacré-Coeur de Montréal; Centre de santé et de services sociaux de TroisRivières (Charbonney), Université de Montréal, Montréal, Que.

Correspondence to: Emmanuel Charbonney, emmanuel.charbonney@ umontreal.ca

CMAJ 2016. DOI:10.1503 /cmaj.150609
A 78-year-old alert woman in hospital was being fed through a nasogastric tube because of deconditioning. She was taking acetylsalicylic acid for ischemic cardiomyopathy, and a vitamin $\mathrm{K}$ antagonist for atrial fibrillation and a recent axillobifemoral bypass thrombosis. She had a permanent right-side nephrostomy after receiving an injury to the ureter during the bypass surgery. She did not have swallowing deficits or any neurologic impairment, but her caloric intakes were insufficient.

The nasogastric tube malfunctioned and was replaced with a new one, using a metal guide wire; the patient coughed briefly during the replacement procedure. Afterwards, she reported high lumbar and retrothoracic pain on the right side, just above the nephrostomy. A control chest radiograph, ordered by the treating physician, showed that the feeding tube had been incorrectly placed into the posterior pleural space and had passed through the right bronchus and lower lobe of the lung (Figure 1A). No feeding had been started and no hemoptysis was present. Removal of the feeding tube led to a pneumothorax, which was drained (Figures 1B, 1C). The patient was monitored in the intensive care unit for 24 hours, without further complications.
Incorrect placement of nasogastric tubes can lead to numerous complications, including bronchopleural fistula, pneumothorax and aspiration pneumonia. ${ }^{1}$ Other lesions of the nasopharyngeal, laryngeal, esophageal and airway structures may occur; however, the structure of the lung parenchyma is more prone to perforation.

Patients with suppressed cough or gag reflexes, or with impaired consciousness (e.g., critically ill patients) are at highest risk for incorrect placement of the nasogastric tube. Chest radiography is the gold standard for confirming appropriate placement of a nasogastric tube. If the feeding tube is blindly inserted, radiographic confirmation of correct placement is recommended before administration of medication or feeding. ${ }^{2}$ There should be no exceptions to this rule, because other methods (e.g., auscultation of air blow, examination of gastric aspirate and measurement of its $\mathrm{pH}$ ) are unreliable. ${ }^{3}$

\section{References}

1. Metheny NA. Preventing respiratory complications of tube feedings: evidence-based practice. Am J Crit Care 2006;15:360-9.

2. Practice Alert: Verification of feeding tube placement (blindly inserted). Aliso Viejo (CA): American Association of CriticalCare Nurses; 2009 [revised]. Available: www.aacn.org/wd/ practice/docs/practicealerts/verification-feeding-tube-placement.pdf ?menu=aboutus (accessed 2015 Sept. 9).

3. Lemyze M. The placement of nasogastric tubes. CMAJ 2010; 182:802. 